\title{
Effect of ELMs on rotation and momentum confinement in H-mode discharges at JET
}

\author{
Versloot, T.W.; de Vries, P.C.; Giroud, C.; Hua, M.-D.; Beurskens, M.; Brix, M.; Eich, T.; de la Luna, E.; \\ Tala, T.; Naulin, Volker \\ Total number of authors: \\ 11
}

Published in:

Proceedings

Publication date:

2009

Document Version

Early version, also known as pre-print

Link back to DTU Orbit

Citation (APA):

Versloot, T. W., de Vries, P. C., Giroud, C., Hua, M-D., Beurskens, M., Brix, M., Eich, T., de la Luna, E., Tala, T., Naulin, V., \& Zastrow, K. D. (2009). Effect of ELMs on rotation and momentum confinement in H-mode discharges at JET. In Proceedings (pp. P2.170). European Physical Society. Europhysics Conference Abstracts No. 33E

\section{General rights}

Copyright and moral rights for the publications made accessible in the public portal are retained by the authors and/or other copyright owners and it is a condition of accessing publications that users recognise and abide by the legal requirements associated with these rights.

- Users may download and print one copy of any publication from the public portal for the purpose of private study or research.

- You may not further distribute the material or use it for any profit-making activity or commercial gain

- You may freely distribute the URL identifying the publication in the public portal 
EFDA-JET-CP(09)06/24

T.W. Versloot, P.C. de Vries, C. Giroud, M.-D. Hua, M. Beurskens, M. Brix, T. Eich E. de la Luna, T. Tala, V. Naulin, K.D. Zastrow and JET EFDA contributors

\section{Effect of ELMs on Rotation and Momentum Confinement in H-mode Discharges at JET}


"This document is intended for publication in the open literature. It is made available on the understanding that it may not be further circulated and extracts or references may not be published prior to publication of the original when applicable, or without the consent of the Publications Officer, EFDA, Culham Science Centre, Abingdon, Oxon, OX14 3DB, UK."

"Enquiries about Copyright and reproduction should be addressed to the Publications Officer, EFDA, Culham Science Centre, Abingdon, Oxon, OX14 3DB, UK." 


\section{Effect of ELMs on Rotation and Momentum Confinement in H-mode Discharges at JET}

T.W. Versloot ${ }^{1}$, P.C. de Vries ${ }^{2}$, C. Giroud ${ }^{2}$, M.-D. Hua ${ }^{3}$, M. Beurskens ${ }^{2}$, M. Brix ${ }^{2}$, T. Eich ${ }^{4}$, E. de la Luna ${ }^{5}$, T. Tala ${ }^{6}$, V. Naulin ${ }^{7}$, K.D. Zastrow ${ }^{2}$ and JET EFDA contributors*

JET-EFDA, Culham Science Centre, OX14 3DB, Abingdon, UK

${ }^{I}$ FOM Institute Rijnhuizen, Association EURATOM-FOM, Nieuwegein, the Netherlands ${ }^{2}$ EURATOM-UKAEA Fusion Association, Culham Science Centre, OX14 3DB, Abingdon, OXON, UK

${ }^{3}$ Imperial College, SW7 2BY, London, UK

${ }^{4}$ Max-Planck-Institut fur Plasmaphysik, EURATOM Assoziation, Garching D-85748, Germany

${ }^{5}$ Laboratorio Nacional de Fusión, Asociación EURATOM-CIEMAT, Madrid, Spain

${ }^{6}$ Association EURATOM-Tekes VTT, P.P. Box 1000, 02044 VTT, Finland

${ }^{7}$ Association EURATOM-Risф DTU, Fredericksborgvej 388, Roskilde, Denmark

* See annex of F. Romanelli et al, "Overview of JET Results",

(Proc. $22^{\text {nd }}$ IAEA Fusion Energy Conference, Geneva, Switzerland (2008)).

Preprint of Paper to be submitted for publication in Proceedings of the

36th EPS Conference on Plasma Physics, Sofia, Bulgaria.

(29th June 2009 - 3rd July 2009) 



\section{INTRODUCTION}

Momentum transport is an active area of research in many tokamaks due to the role of rotational shear in turbulence suppression and global plasma confinement. However, at present it is not well understood how plasma rotation profiles are affected by the operating conditions. A raw linear scaling between global energy and momentum confinement has been observed in many devices [1], including ASDEX [2], DIII-D [3] and JET [4], although the presence of a large scatter suggests a difference in their local behaviour.

A major influence on the confinement in H-mode discharges is observed during Edge Localised Modes (ELMs) in which the repetitive collapse of the pedestal causes an ejection of energetic particles from the plasma. In this process, both kinetic energy and angular momentum can be lost. In database analysis at JET [4] it has been observed that the rotation velocity is reduced with higher ELM frequency. Furthermore, studies of ELM associated energy losses in multiple devices show energy losses in the order of 5-20\% [5-6]. However, the magnitude of the momentum losses are not well known and might not necessarily be of

similar magnitude. For the better understanding of the observed momentum confinement it is important to investigate the momentum loss and the influence on the plasma rotation profiles.

In this paper the measured changes in plasma profiles of angular frequency $\left(\omega=v_{\varphi} / R\right)$, temperature $\left(T_{i}, T_{e}\right)$ and density $\left(n_{e}\right)$ will be discussed in order to assess the momentum and thermal energy losses. The confinement characteristics of several type-I ELMy H-modes are presented. The ELM induced losses are estimated while taking the measurement capabilities into consideration, in order to quantify the observed variations in confinement.

\section{GLOBAL CONFINEMENT}

From scaling laws, it is found that the energy confinement decreases with absorbed power $\left(\sim \mathrm{P}^{-0.69}, \tau_{\mathrm{IPB} 98(y, 2)}\right)$. Figure 1a shows the time evolution of an H-mode discharge $\left(\mathrm{B}=1.6 \mathrm{~T}, \mathrm{I}_{\mathrm{p}}=\right.$ 1.6MA) with stepped Neutral Beam (NBI) power to vary the stored energy and momentum. The NBI was stepped in three phases with $\mathrm{P}_{\text {low }}(4.5 \mathrm{MW}), \mathrm{P}_{\text {med }}(7.5 \mathrm{MW})$ and $\mathrm{P}_{\text {high }}(12 \mathrm{MW})$. Steadystate is obtained roughly $1 \mathrm{~s}$ after each step during both $\mathrm{P}_{\text {med }}$ and $\mathrm{P}_{\text {high }}$, with $\mathrm{P}_{\text {low }}$ still showing a slight increase in density. Each phase is characterised by type-I ELMs with increasing frequency $\left(f_{\text {ELM }}\right.$ ) of approximately 15,30 and $60+\mathrm{Hz}$ respectively. The increase in $\mathrm{D}_{\alpha}$ radiation offset suggests a slightly higher particle recycling at the plasma edge.

However, the edge line integrated density shows only minor variations and the effect is thus assumed to be constant. In the early phases, total kinetic energy $\left(W_{t h}=\int 3 / 2 k\left(n_{i} T_{i}+n_{e} T_{e}\right) d V\right)$ and total angular momentum $\left(\mathrm{L}_{\varphi}=\int \mathrm{n}_{\mathrm{i}} \mathrm{m}_{\mathrm{i}} \mathrm{Rv} \mathrm{v}_{\varphi} \mathrm{dV}\right)$ increase with injected power due to the coupling between torque and power in NBI heating. Most interesting to notice is the reduction in $\mathrm{L}_{\varphi}$ at $\mathrm{P}_{\text {high }}$, which is a consequence of both a drop in core density and a large reduction in angular frequency near the pedestal top $\left(\mathrm{R}_{\mathrm{ped}} \sim 3.8 \mathrm{~m}, \mathrm{r} / \mathrm{a} \sim 0.92\right)$. This reduction in $\mathrm{L}_{\varphi}$ results in a further decrease in momentum confinement $\left(\tau_{\varphi}\right)$ in comparison to the energy confinement $\left(\tau_{\mathrm{E}}\right)$ although additional 
torque is applied. The global ratio of energy to momentum confinement $\left(\mathrm{R}_{\tau}=\tau_{\mathrm{E}} / \tau_{\varphi}\right)$ thus changes from $0.8 \pm 0.2$ at $\mathrm{P}_{\text {low }}$ to $1.1 \pm 0.1$ at $\mathrm{P}_{\text {high }}$ (see Figure $1 \mathrm{~b}$ ).

Separating the confinement in core and edge components by determining the stored fractions in the pedestal enclosed volume (as in [4,5]) shows that a large part of the ratio change is caused by the pedestal region, $R_{\tau \text {,edge }}=1.80 \pm 0.37$. The significant reduction in the tj,edge is consistent with the large reduction in $\mathrm{w}$ near the pedestal top which, combined with the large elliptical volume, contributes significantly to the total momentum. Additionally, a decrease in the edge thermal mach number, defined as the ratio of fluid over thermal velocity $\left(\mathrm{M}_{\mathrm{th}}=\mathrm{v}_{\varphi} / \sqrt{ }\left(\mathrm{eT}_{\mathrm{i}} / \mathrm{m}\right)\right.$ is seen from 0.30 to 0.15 (see Figure 1c). This is in agreement with the observation that the pedestal conditions play a major role in the global confinement and, more evidently, suggests that $\tau_{\varphi}$ does not scale as $\tau_{\mathrm{E}}$ with increasing $\mathrm{f}_{\mathrm{ELM}}$.

\section{ELM DYNAMICS AND MOMENTUM LOSS}

An explanation for the change in Rt could be the change in ELM associated losses. ELM cycle dynamics are characterised by a fast drop in pedestal pressure gradient $(\Delta t=0.1-0.2 \mathrm{~ms})$, followed by a build up due to core transport until the critical gradient is reached and a successive ELM is triggered [6]. Unfortunately, the 10ms integration time of the core Charge Exchange Recombination Spectroscopy (CXRS) [7] system is too long to obtain time resolved information during the initial ELM crash. Instead, for low frequency ELM cycles $\left(\mathrm{f}_{\mathrm{ELM}}<30 \mathrm{~Hz}\right)$ a separation between pre-ELM ($\left.15 \mathrm{~ms}<\mathrm{t}-\mathrm{t}_{\mathrm{ELM}}<-5 \mathrm{~ms}\right)$ and post-ELM $\left(5 \mathrm{~ms}>\mathrm{t}-\mathrm{t}_{\mathrm{ELM}}<10 \mathrm{~ms}\right)$ is made to estimate relative changes. A consequence of this method however is the systematic underestimation of the absolute drop due to the quick build up of the pedestal. In Figure $2 \mathrm{a}, \mathrm{b}$ the averaged pre- and post-ELM profiles are shown for $\mathrm{w}$ and $\mathrm{T}_{\mathrm{i}}$ during a fixed input power $\mathrm{H}$-mode discharge $\left(\mathrm{B}=2.2 \mathrm{~T}, \mathrm{I}_{\mathrm{p}}=2.0 \mathrm{MA}\right)$ with typeI ELMs at $\mathrm{f}_{\mathrm{ELM}} \sim 20 \mathrm{~Hz}$. A clear drop in the angular frequency profile is observed from r/a $\sim 0.65$ outwards while the ion temperature drop appears to be smaller and penetrates less deeply. Using a coherent data sampling method [5], the time evolution of the $\omega$ and $\mathrm{T}_{\mathrm{i}}$ profile can be obtained, as shown in Figure 2d,e, together with ne from High Resolution Thompson Scattering (HRTS) and Te from Electron Cyclotron Emission (ECE) measurements at approximately the same flux surface position. From the time dynamics it seems that the build up of $\omega$ has not reached a stable value before the next ELM. Notice the good agreement in magnitude and time evolution between $\mathrm{T}_{\mathrm{e}}$ and $\mathrm{T}_{\mathrm{i}}$ close to $\mathrm{R}_{\text {ped. }}$. The HRTS and ECE measurements are selected in accordance to the CXRS time resolution in order to have a direct comparison between all parameters. In Figure 3a, the radial drop profile for all parameters are shown normalised to the pre-ELM profile. A consistently larger drop in angular frequency $\left(\Delta \omega / \omega_{\text {pre }}=35 \pm 4 \%\right)$ is observed relative to temperature $\left(\Delta \mathrm{T}_{\mathrm{e}} / \mathrm{T}_{\mathrm{e}, \text { pre }}=18 \pm 7 \%\right.$, $\left.\Delta \mathrm{T}_{\mathrm{i}} / \mathrm{T}_{\mathrm{i}, \mathrm{pre}}=18 \pm 3 \%\right)$ and electron density $\left(\Delta \mathrm{n}_{\mathrm{e}} / \mathrm{n}_{\mathrm{e}, \mathrm{pre}}=10 \pm 2 \%\right)$ near the pedestal top. Alternatively, the ne drop profile determined by deconvolution of the line integration measurements [8] is in agreement with the HRTS which improves the certainty on the derived density profile change.

The momentum and energy density profiles are calculated using the average pre- and post-ELM profiles of all parameters. The ion density is estimated using a single impurity correction factor 
from Brehmsstrahlung $\left(\mathrm{Z}_{\mathrm{eff}} \sim 1.5\right)$. The total loss of angular momentum $\left(\Delta \mathrm{L}_{\varphi}\right)$ and energy $\left(\Delta \mathrm{W}_{\text {th }}\right)$ is then determined by radial integration of the drop profile up to the last CXRS measurements with $\mathrm{R} \sim \mathrm{R}_{\text {ped }}$. The results for several $\mathrm{H}$-mode discharges in which all diagnostics were available are shown in Figure $3 \mathrm{~b}$. The momentum drop is consistently larger than the drop in thermal energy. For the discharges presented in this section (black dots), the average $\Delta \mathrm{L}_{\varphi} / \mathrm{L}_{\varphi}$ is $9 \pm 1 \%$ in comparison to $\Delta \mathrm{W}_{\mathrm{th}} / \mathrm{W}_{\text {th }}=5 \pm 1 \%$. Normalised to the pre-ELM pedestal stored values, this would be $22 \pm 3 \%$ and $16 \pm 5 \%$ respectively. The uncertainties are derived from the averaging method un these three pulses under similar plasma conditions.

\section{CONCLUSIONS AND DISCUSSION}

The ELM induced loss in angular momentum was found to be consistently larger relative to the thermal energy drop. The difference is mainly caused by the significant drop in angular frequency compared to the temperature from r/a 0.65 outwards. With the large contribution of the pedestal to the global confinement, the ELM losses contribute significantly to the change in confinement. The increased momentum losses thus offer an explanation for the observed reduction in the average angular frequency with increasing $\mathrm{f}_{\text {ELM }}$. This would be especially important when the fELM is near the build up time of the pedestal, resulting in a further lowering of momentum confinement time and a change in confinement time ratio. For a better understanding of the plasma global confinement it is therefore important to study the loss mechanisms and their relation to the pedestal conditions.

\section{ACKNOWLEDGEMENTS}

This work, supported by the European Communities under the contract of Association between EURATOM, FOM and UKAEA, was carried out in the framework of the European Fusion Programme. The views and options expressed herein do not necessarily reflect those of the European Commission.

\section{REFERENCES}

[1]. T. Tala et al, Plasma Phys. Control. Fusion 49, 2007, B291-B302

[2]. D. Nishijima et al, Plasma Phys. Control. Fusion, 47, 2005, 89-115

[3]. W.M. Solomon et al, Plasma Phys. Control. Fusion, 49, 2007, B313-B324

[4]. P.C. de Vries et al, Nucl. Fusion, 48, 2008, 065006

[5]. M.N.A. Beurskens et al, in Fusion Energy 2008 (Proc. 22nd Int. Conf. Geneva, 2008) (Vienna: IAEA) CDROM file EX/P3-4 and http://www-naweb.iaea.org/napc/physics/FEC/FEC2008/ html/index.htm

[6]. A. Loarte et al, Plasma Phys. Control. Fusion 44, 2002, 1815-1844

[7]. C. Giroud et al, Rev. Sci. Instrum. 79, 2008, 10F525

[8]. M. Brix et al, to be submitted to PPCF 

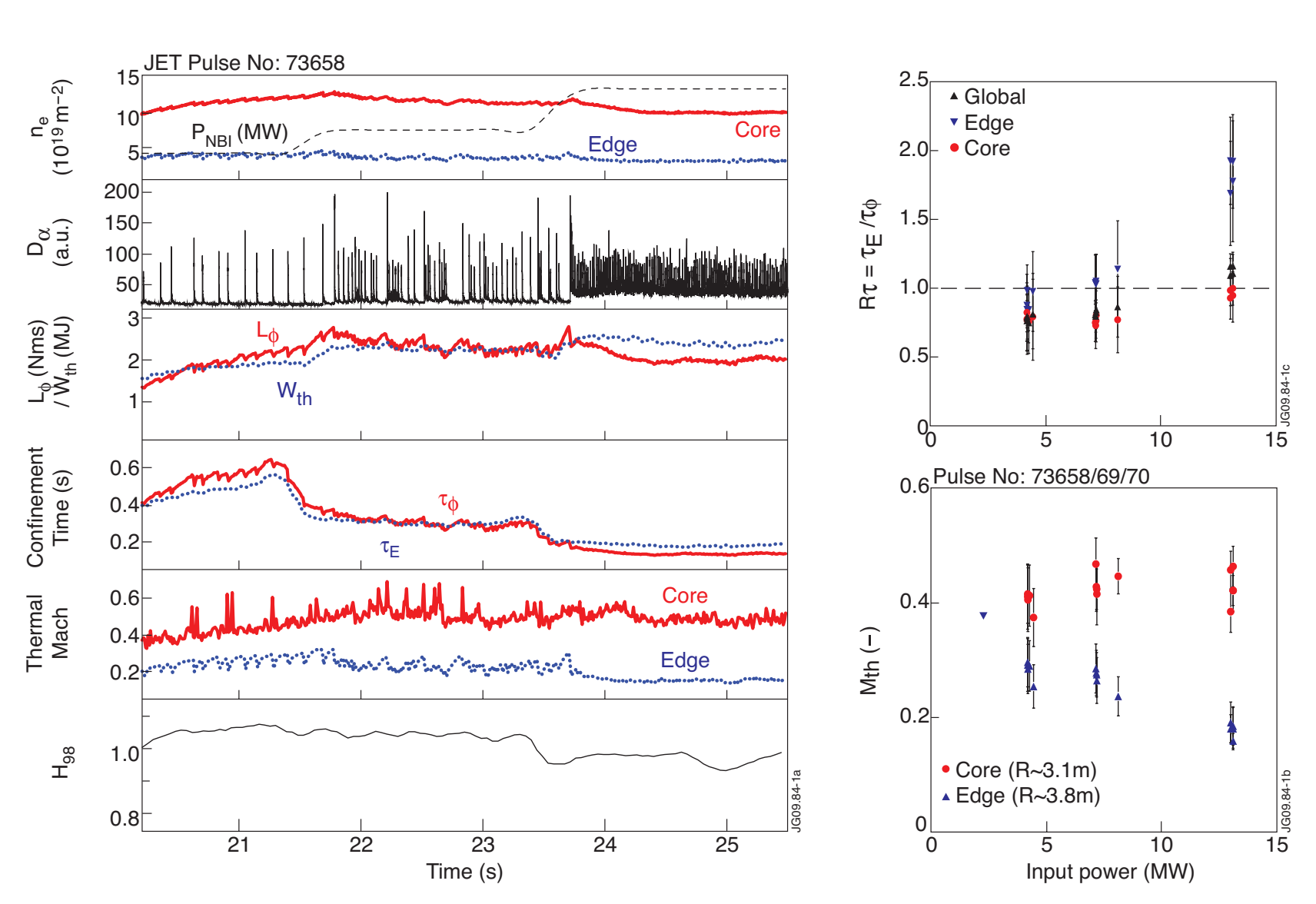

Figure 1: (a) Waveforms of stepped power Pulse No: 73568 showing change in confinement with $f_{\text {ELM }}$, (b) Thermal Mach number versus input power in plasma core $(\bullet)$ and near the pedestal top $(\mathbf{\Delta}),(c)$ Confinement time ratio versus input power separated for global $(\mathbf{\Delta})$, edge $(\boldsymbol{\nabla})$ and core $(\bullet)$ region 

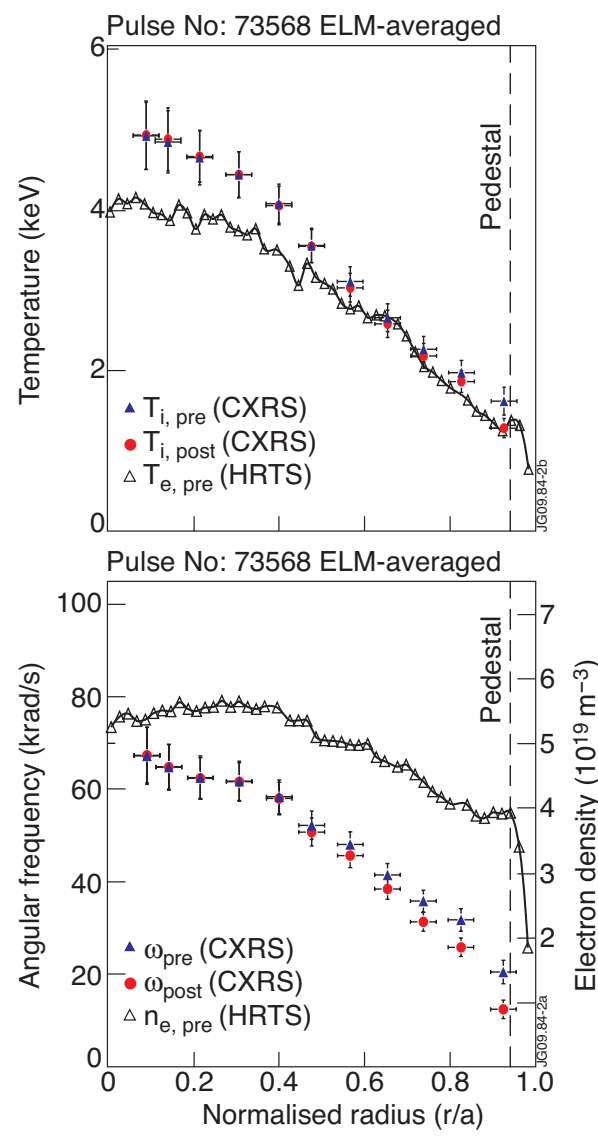

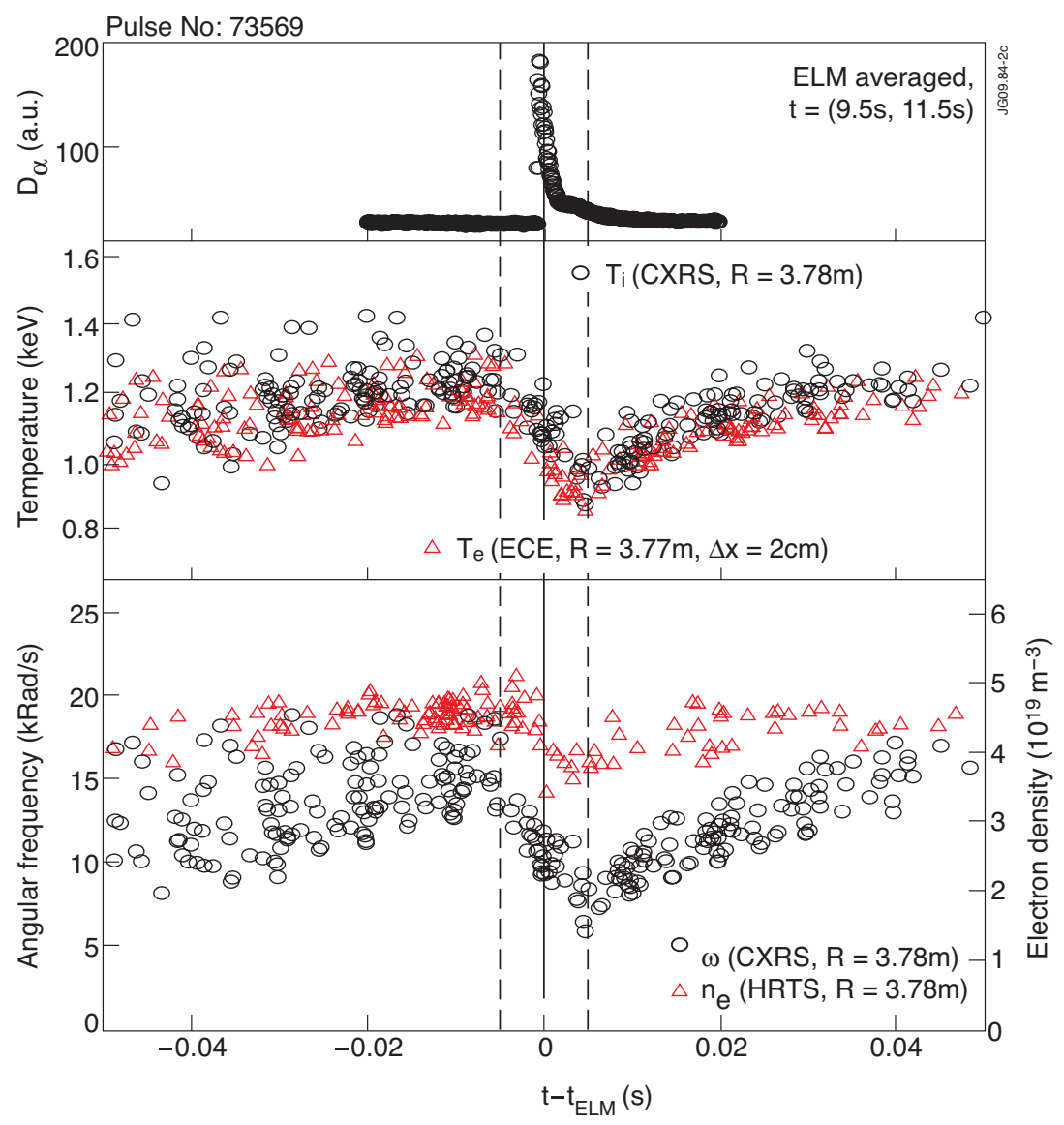

Figure 2: (a) ELM-averaged angular frequency profile at pre-ELM (•) and post-ELM(•), average pre-ELM electron density from HRTS $(\boldsymbol{\Delta})$ is shown to indicating the pedestal location. (b) ion and electron temperature (c) Evolution of $D_{\alpha}$ relative to the ELM onset using coherent data sorting for $T_{i}(C X R S, 10 m s), T_{e}(E C E$, sampled at $100 H z), \omega(C X R S$, $10 \mathrm{~ms})$ and $n_{e}(\mathrm{HRTS}, 20 \mathrm{~Hz})$. The last CXRS measurement point is shown with its position used to select the closest channel of the HRTS and ECE signals. Data points within $\pm 5 \mathrm{~ms}$ around tELM are excluded from the analysis to prevent overlap between pre- and post-ELM profiles
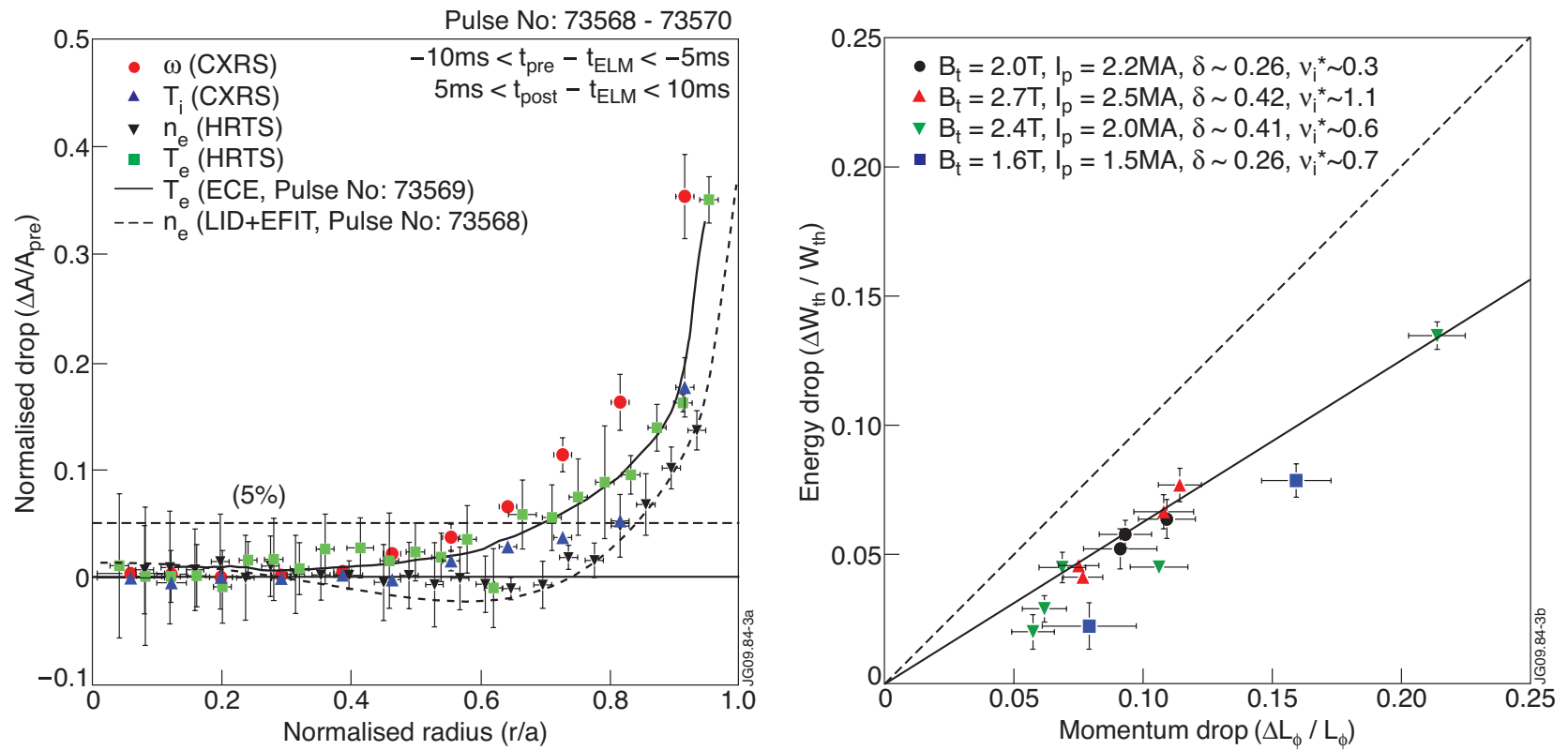

Figure 3: (a) ELM-averaged normalised drop profiles versus normalised minor radius. (b) Normalised total momentum drop $\left(\Delta L / L_{\varphi}\right)$ versus normalised thermal energy $\left(\Delta W / W_{t h}\right)$ for several discharges at varying field, plasma current and applied NB heating. Notice all values show a larger momentum drop by a factor 1.6. 